\title{
Comparison of liquid and gaseous oxygen for domiciliary portable use
}

\author{
S H Lock, G Blower, M Prynne, J A Wedzicha
}

\begin{abstract}
Background Liquid oxygen is available for portable use and may have advantages over gas cylinders.

Methods The use and acceptability of liquid and gaseous oxygen was compared in 15 patients with chronic lung disease who had shown an improvement of at least $10 \%$ in assessments of exercise tolerance and breathlessness with standard portable oxygen. Gaseous and liquid portable oxygen were provided in random order for two eight week periods, and assessments consisted of six minute walking tests, lung function tests, chronic respiratory disease index questionnaires, and diary cards.
\end{abstract}

Results The walking distance was not significantly affected by the weight of the equipment with either system. Patients used the liquid oxygen for significantly longer (23.5 hours a week) than the gas cylinder (10 hours a week). When using liquid oxygen patients went out of the house on average for 19.5 hours a week, compared with 15.5 hours a week with gaseous oxygen. The liquid oxygen system was preferred because the oxygen lasted longer, filling was easier, and the canister was easier to carry.

Conclusions Liquid oxygen for portable treatment may be of benefit in selected patients with chronic lung disease.

Portable oxygen therapy has been shown to have important benefits in patients with chronic lung disease, improving exercise tolerance and breathlessness during exertion. ${ }^{1-6}$ In the United Kingdom portable oxygen is supplied in gaseous form in small cylinders weighing $2.4 \mathrm{~kg}$ and these are refilled in the patient's home from larger ( $F$ size) cylinders. In other countries, however, such as the United States and France, portable oxygen is supplied in liquid form in portable canisters, which can be filled from a larger reservoir at home. These have the advantage of providing eight hours of oxygen at a flow rate of $21 / \mathrm{min}$, compared with a maximum of two hours of oxygen at this flow rate with the gas cylinders.

A longer duration of oxygen supply may benefit patients with chronic respiratory disease by enabling them to spend more time out of doors, thus improving quality of life and enhancing rehabilitation. A previous study ${ }^{1}$ suggested that the weight of portable liquid oxygen equipment may negate any improvement in exercise tolerance. Modern equip- ment, however, is lighter $(3.5 \mathrm{~kg}$ when full, $2.5 \mathrm{~kg}$ when empty) and less cumbersome for the patient to carry.

The purpose of this study was to compare the use and acceptability of gaseous and liquid systems in patients with chronic lung disease who use portable oxygen at home. Despite provision of liquid oxygen in other countries few formal comparisons with gaseous oxygen for portable use have been carried out. ${ }^{7}$

\section{Methods \\ PATIENTS}

We studied 15 patients with chronic lung disease ( 13 with chronic airflow limitation, one with pulmonary fibrosis, and one with kyphoscoliosis), all mobile and clinically stable. They had all undergone a standard portable oxygen assessment and had improved their walking distance or their visual analogue scale score for breathlessness (or both) by at least $10 \%{ }^{8}$ Details of the 15 patients (12 male, three female) are shown in the table. Eleven of the patients were having long term oxygen therapy and eight were using portable oxygen before the study. In one patient oxygen was delivered by the transtracheal route. The patients were all chosen as non-smokers, but were nevertheless reminded about not smoking cigarettes with the oxygen equipment in the house. The study was approved by the ethics committee of the Royal Brompton National Heart and Lung Hospitals.

\section{STUDY DESIGN AND ASSESSMENTS}

The 15 patients were randomly allocated to start on liquid oxygen canisters (Puritan Bennett Companion 1000) or gaseous oxygen cylinders (DeVilbiss Health Care UK Ltd) for eight weeks, after which they were changed to the other form of treatment for a further eight weeks. A 3 litre Companion Reservoir of liquid oxygen was delivered every two weeks to the patient's home. Patients were instructed to keep the reservoir in a ventilated room

Details of the patients

\begin{tabular}{lcl}
\hline & Mean & $S D$ \\
\hline Age (y) & 62 & 7 \\
$\mathrm{PaO}_{2}(\mathrm{kPa})$ & 6.98 & 1.46 \\
$\mathrm{PaCO}_{2}(\mathrm{kPa})$ & 6.97 & 1.25 \\
$\mathrm{FEV}_{1}(\mathrm{l} / \mathrm{min})$ & 0.76 & 0.33 \\
$\mathrm{FVC}(\mathrm{l})$ & 1.84 & 0.57 \\
$\mathrm{Kco}(\mathrm{mmol} / \mathrm{min} / \mathrm{kPa} / \mathrm{l})$ & 0.91 & 0.36 \\
\hline
\end{tabular}

$\mathrm{PaO}_{2}$-arterial oxygen tension; $\mathrm{PaCO}_{2}$-arterial carbon dioxide tension; FEV - forced expiratory volume in one second; FVC-forced vital capacity; Kco-transfer coefficient. 
away from fires because liquid oxygen evaporates steadily from the reservoirs and portable units, allowing the gas to escape slowly. They were taught how to fill and use the liquid containers by a physiotherapist. Small gas cylinders were refilled from standard F size cylinders.

The forced expiratory volume in one second $\left(\mathrm{FEV}_{1}\right)$ and forced vital capacity (FVC) were measured with a Morgan dry spirometer, and estimations of the transfer coefficient for carbon dioxide (KCO) were performed in duplicate (PK Morgan Transfertest machine). Arterialised ear lobe blood gases were obtained with the patients at rest and after 20 minutes alternately breathing air and oxygen from the gas cylinder and from the liquid oxygen canister. ${ }^{9}$ These were analysed with a Radiometer ABL 3 blood gas analyser.

After two practice walks patients performed standard six minute walking tests as a baseline with the physiotherapist carrying the oxygen supply; two further walks were then performed in random order with the patient carrying either liquid or gaseous oxygen. ${ }^{10}$ The walking tests were repeated eight and 16 weeks later with the equipment that the patient had been using at home for the previous eight weeks. Distance walked and visual analogue scale scores for breathlessness were recorded. ${ }^{11}$

The Chronic Respiratory Disease Index Questionnaire was administered, as an assessment of quality of life, every four weeks by a nursing sister in the outpatient department who was not concerned in other assessments. ${ }^{12}$ Patients were allowed to see the answers they had given on previous visits. ${ }^{13}$ They also kept a diary card at home throughout the study, recording the number of hours they spent each day (a) using the portable systems, $(b)$ out of doors, and $(c)$ using their oxygen concentrators.

\section{STATISTICS}

Student's paired (two tailed) $t$ test was used to compare blood gas measurements and lung function, and the results are presented in terms of mean differences and $95 \%$ confidence intervals $(\mathrm{CI})$ of the differences. Data from the walking tests, visual analogue scale scores, and diary card entries were analysed with Wilcoxon one sample test. ${ }^{14}$

\section{Results}

The patients' arterial oxygen tension $\left(\mathrm{PaO}_{2}\right)$ values when they were breathing liquid oxygen (mean $9.98 \mathrm{kPa}$ ) and gaseous oxygen (mean $10.65 \mathrm{kPa}$ ) were similar (mean difference $0.97 \mathrm{kPa}, 95 \% \mathrm{CI}-2.61$ to $+4.56 \mathrm{kPa})$. There were also no significant differences between the following measurements made at the initial assessment: distance walked on the initial baseline walk (median $250 \mathrm{~m}$ ) and the walk with liquid oxygen (median $250 \mathrm{~m}$ ) (difference between medians $5.0 \mathrm{~m}, 95 \% \mathrm{CI}-5$ to $+12.5 \mathrm{~m}$ ); the initial baseline walk and the walk with gaseous oxygen (median $255 \mathrm{~m}$ ) (difference between medians $0.25 \mathrm{~m}, 95 \% \mathrm{CI}$ -10 to $+13 \mathrm{~m}$ ); the walks with liquid and gaseous oxygen (difference between medians $2.5 \mathrm{~m}, 95 \% \mathrm{CI}-8$ to $+15 \mathrm{~m}$ ). Visual ana-

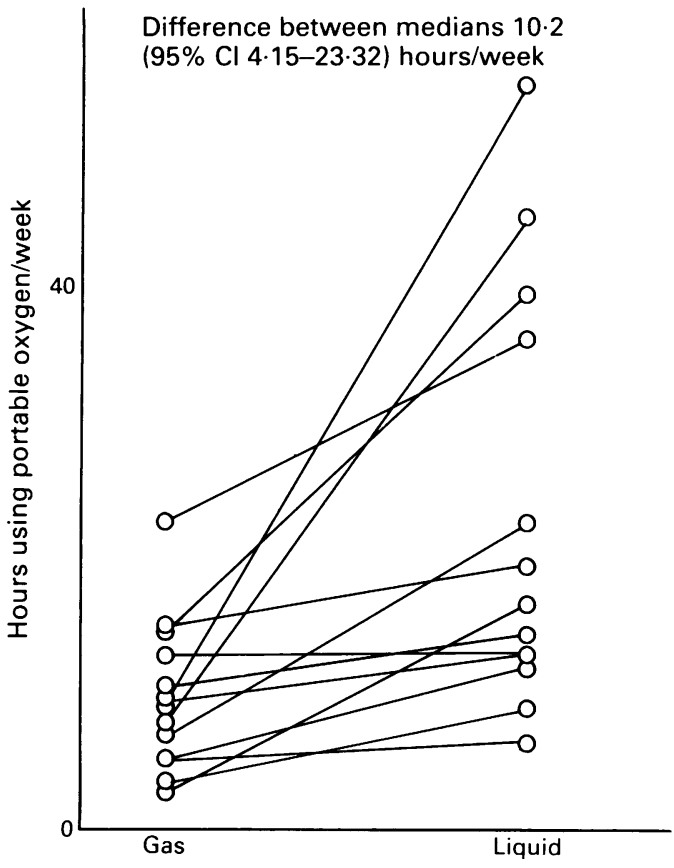

Figure 1 Hours of portable oxygen use per week with liquid and gaseous oxygen.

logue scale scores for breathlessness were also similar after the two walking tests. The baseline walking distance was greater after the eight weeks spent using liquid oxygen than at the initial baseline walk (difference $25 \mathrm{~m}, 95 \%$ CI 5 to $42.5 \mathrm{~m}$ ). There was no significant change in walking distance after eight weeks of gaseous oxygen. There were no significant changes in spirometric values or arterial blood gas tensions at any time during the study.

Information from diary cards was available for only 13 patients. The patients used the liquid oxygen for significantly longer (median 23.5 hours a week) than the gas cylinder ( 10 hours a week, $95 \%$ CI 4.2 to 23.3 hourssee fig 1 ). When using gaseous oxygen patients went out of the house on average 15.5 hours a week, whereas with liquid oxygen they went out 19.5 hours a week (fig 2), a small but significant difference $(95 \% \mathrm{CI}, 0.9$ to $7 \cdot 1$ hours $)$. When they had a gas cylinder patients spent a median of 114 hours a week using their oxygen concentrator, whereas with liquid oxygen they spent a median of 99.6 hours a week using their concentrator (difference between medians 13.1 hours, $95 \%$ CI 1.57 to 27.92 hours).

The questionnaire did not shown any consistent change in any of its four measures (dyspnoea, fatigue, mastery, and emotional function) during the study.

Of the 15 patients, 11 said that they preferred the liquid oxygen because it lasted longer and carrying and filling were easier. One patient preferred the gaseous oxygen, two patients had no preference, and another found portable oxygen of no subjective benefit.

\section{Discussion}

This randomised study has shown that portable oxygen delivered in liquid form for domiciliary use has advantages over standard gaseous oxygen. The longer duration of liquid oxygen supply enables patients to spend more time using portable oxygen and going out of the house. Most patients preferred the liquid 
Figure 2 Hours spent out of doors per week with liquid and gaesous oxygen.

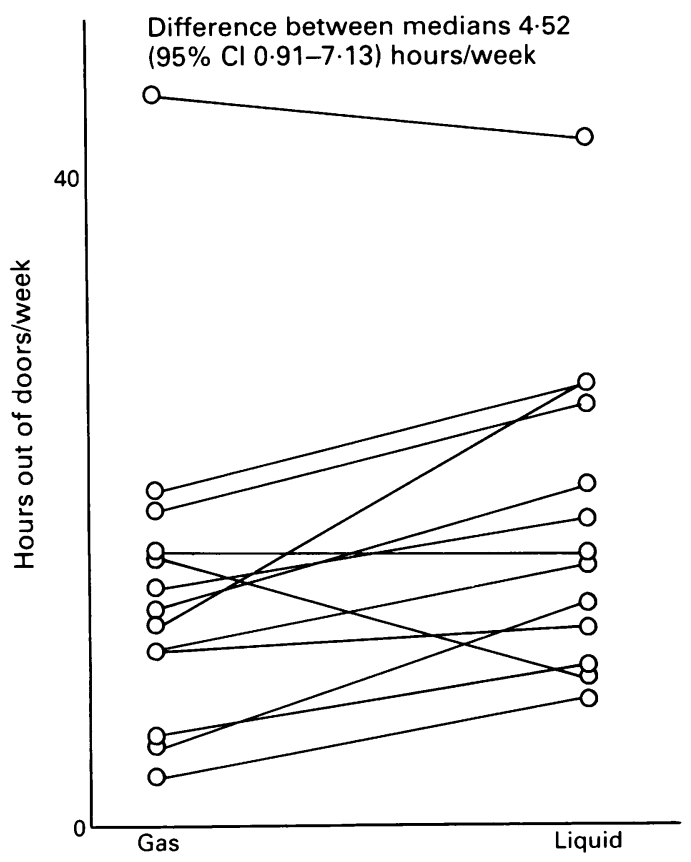

oxygen system, using it more than gaseous oxygen. Liquid oxygen allowed greater freedom of activity and the canisters were easier to fill and more comfortable to carry.

A previous study of portable liquid oxygen performed in 1977 in patients with chronic airflow limitation ${ }^{1}$ suggested that the weight of the equipment counteracted any increase in exercise tolerance. We found no adverse effect on the walking distance or the visual analogue scale score for breathlessness secondary to the weight of equipment. The weight of the liquid system can be reduced further by partially filling the canisters with just enough oxygen for the required number of hours.

The patients used the liquid oxygen more than twice as much as the gaseous oxygen, though with liquid oxygen they went out of the house only about half as often again as when they were using gaseous oxygen. The reason for this was that patients used the oxygen devices instead of their concentrators in their gardens and in the house despite a request to restrict the portable equipment to outdoor use. The increased time spent using portable oxygen and being out of the house should be beneficial to the patient and improve rehabilitation, as suggested by the small but significant increase in exercise tolerance shown after the eight weeks using liquid oxygen. The quality of life questionnaire did not show any consistent changes in this study, which may be due to the small number of patients and the short term nature of the study. A recent French study showed that patients using portable oxygen in addition to fixed oxygen supplies used more oxygen in total than those without a portable system. They were unable to show any difference in total oxygen use between liquid and gaseous systems, but did not compare the amount of portable oxygen used with the two systems.

All the patients in our study used oxygen at a standard flow rate of 2 litres a minute. Occasionally, however, higher oxygen flow rates are known to be required for achieving optimum benefit and correcting arterial oxygen desaturation during exercise, particularly in patients with pulmonary fibrosis. ${ }^{5}$ The provision of liquid oxygen is a great advantage for this group of patients, where the supply of adequate portable gaseous oxygen presents considerable difficulties as the cylinders last for only short periods. Oxygen can be conserved by up to $50 \%$ by using transtracheal oxygen delivery, enabling gas cylinders to last longer, but these systems are invasive and less popular in this country than in the United States. ${ }^{15}$ Oxygen conserving devices are also available, but again are rarely used in Britain as they are generally unreliable in the degree to which they conserve oxygen. ${ }^{16}$

We believe that liquid oxygen for portable domiciliary use should be available for a small, carefully selected group of patients with chronic lung disease. These patients should be shown to benefit from portable oxygen therapy in a standard assessment ${ }^{8}$ and should be regularly using their portable gaseous oxygen for substantial periods. Patients, who depend on supplemental oxygen for 24 hours a day or who require high flow rates of oxygen are also candidates for liquid oxygen.

The provision of liquid oxygen equipment and its delivery to the patient's home is costly, though exact figures are not available for the United Kingdom. Portable oxygen in gaseous form is also expensive and at a certain level of use (more than four hours a day) the costs will be equivalent for the two delivery systems. Liquid oxygen might be especially suitable for the patient with chronic respiratory disability who could possibly return to regular employment if an eight hour supply of portable oxygen were conveniently available.

We would like to thank the technicians in the lung function laboratory for their assistance, and Miss Elizabeth Paul for help with statistical analysis. We are grateful to Puritan-Bennett and Air Products Ltd for supplying the equipment and liquid oxygen used in this study.

1 Leggett RJE, Flenley DC. Portable oxygen and exercise tolerance in patients with chronic hypoxic cor pulmonale. $B M J$ 1977;ii:84-6.

2 Bradley BL, Garner AE, Billiu D, Messtas JM, Forman J. Oxygen assisted exercise in chronic obstructive lung disease. Am Rev Respir Dis 1978;118:239-43.

3 Waterhouse JC, Howard P. Breathlessness and portable oxygen in chronic obstructive airways disease.Thorax 1983;38:303-6.

4 Woodcock AA, Geddes DM, Gross ER. Oxygen relieves breathlessness in "pink puffers." Lancet 1981;i:907-9.

5 Davidson AC, Leach R, George RJD, Geddes DM. Supplemental oxygen and exercise ability in chronic obstructive airways disease. Thorax 1988;43:965-71.

6 Lilker ES, Karnick A, Lerner L. Portable oxygen in chronic obstructive lung disease with hypoxemia and cor pulmonale. Chest 1975;68:236-41.

7 Vergeret J, Brambilla C, Mounier L. Portable oxygen therapy: use and benefit in hypoxemic COPD patients on long-term oxygen therapy. Eur Respir J 1989;2:20-5.

8 Lock SH, Paul EA, Rudd RM, Wedzicha JA. Portable oxygen therapy: assessment and usage. Respir Med 1991; 85:407-12.

9 Spiro SG, Dowdeswell IRG. Arterialised ear lobe blood samples for blood gas tensions. Br J Dis Chest 1976; 70:263-8.

10 Butland RJA, Pang J, Gross ER, Woodcock AA, Geddes DM. Two-, six-, and twelve-minute walking tests in respiratory disease $B M J 1982 ; 284: 1607-8$

11 Bond $A$, Lader $M$. The use of analogue scales in rating subjective feelings. Br J Med Psychol 1974;74:211-8.

12 Guyatt GH, Berman LB, Townsend M, et al. A new measure of quality of life for clinical trials in chronic lung disease. Thorax 1987;42:773-8.

13 Guyatt GH, Berman LB, Townsend M, Taylor DW. Should study subjects see their previous responses? J Chron Dis 1985;38:1003-7.

14 Gardener MJ, Altman DG. Statistics with confidence. London: British Medical Journal, 1989.

15 Christopher KL, Spofford BT, Petrun MD, et al. A program for transtracheal oxygen delivery. Ann Intern Med 1987; 107:802-8.

16 Moore-Gillon JC. Oxygen conserving delivery devices. Respir Med 1989;83:263-4. 